\title{
Editorial
}

\section{Gamma Capsulotomy: A Valid Option for Refractory Obsessive Compulsive Disorder}

\author{
Manjul Tripathi ${ }^{10}$ Nishanth Sadashiva20 \\ ${ }^{1}$ Department of Neurosurgery, Post Graduate Institute of Medical \\ Education and Research (PGIMER), Chandigarh, India \\ ${ }^{2}$ Department of Neurosurgery, National Institute of Mental Health \\ and Neurosciences (NIMHANS), Bengaluru, Karnataka, India
}

J Neurosci Rural Pract 2022;13:167-168.

Many psychiatric disorders like obsessive compulsive disorder (OCD), anorexia nervosa, and depression are notorious for being refractory to medical management. Contrary to the prevailing nihilism, prior accounts of disputed practices and unfavorable outcomes of psycho surgery, noninvasive or minimally invasive surgical techniques such as stereotactic radiosurgery and stimulation therapies have proven their value in the management of these patients. ${ }^{1}$ Among psychiatric disorders, OCD has been found to be most responsive to surgical interventions. In selected patients, these procedures not only improve the quality of life of the patients by reducing obsessions and compulsions but also provide a socially acceptable life to the patients. ${ }^{2}$

Surprisingly one of the first indications for gamma knife radiosurgery (GKRS) was OCD and Lars Leksell described beneficial effects of bilateral lesioning in the anterior limb of internal capsule. ${ }^{3}$ The corticothalamic bundles run through the lower portion of the anterior limb of internal capsule located between the head of the caudate nucleus and the putamen. ${ }^{4}$ This specific field of functional radiosurgery demands utmost technical expertise as target is identified only through imaging. Functional psychosurgery with GKRS aims at blocking certain interconnecting pathways joining cortical subcortical channels between deep-seated gray and white matter with frontal and temporal lobes. Radiosurgery induces inflammatory changes in the irradiated areas followed by demyelination of the deep-seated white matter that leads to permanent changes causing functional alteration in the white matter cell transmission. The functional radiology in cases of OCD has revealed hypermetabolic changes in the orbital frontal cortex, anterior cingulate region, caudate nucleus, and the thalamus. ${ }^{5}$ Based on these findings, various surgeons have targeted different locations including anterior capsulotomy, tractotomy, and cingulot- omy. A thorough literature search reveals that the ventral anterior internal capsule is the most appropriate target for neuromodulation with excellent long-term safety and efficacy profile. Swedish and American groups have reported that nearly 55 to $70 \%$ patients report significant decrease in their symptomatology assessed on Y-BOCS scale (at least 35\% improvement over baseline score). ${ }^{6}$

I congratulate the authors for bringing this important yet neglected field of radiosurgery to the readers of the eminent journal. It is commendable that the authors have adapted their treatment techniques since the inception of Gamma knife at their center. Authors have presented their experience with nine patients of refractory OCD treated with GKRS. They reported a good response by targeting anterior limb of internal capsule. In a single patient, they target it cingulate gyrus but did not achieve good outcome. Their findings are in sync with the existing literature and definitely add value for practice in the Indian subcontinent. ${ }^{7}$

A few centers from the world have reported complications of anterior capsulotomy such as perilesional edema, hemiparesis, and delayed cyst formation. ${ }^{2,8} \mathrm{~A}$ thorough evaluation of these unsuccessful and rest of the successful cases has revealed several pitfalls in the radio surgical planning of these patients. Paddick in review of the safety and complication profile of anterior capsulotomy found that earlier versions of GKRS suffered some limitations in anterior capsulotomy in view of the relatively increased margin of error, and difficulty in selective beam blocking to spare paramedian structures. The later versions of GKRS such as Perfexion and ICON ensured oblong and elongated shot structures that avoided crosstalk of the radiation in the midline while sparing anterior limb of internal capsule and caudate nucleus alike. Such an approach created a "dose dense radiosurgery" in a 4 to $6 \mathrm{~mm}$ zone of the anterior limb

\author{
Address for correspondence \\ Nishanth Sadashiva, MCh, \\ Department of Neurosurgery, \\ National Institute of Mental \\ Health and Neurosciences \\ (NIMHANS), Bengaluru 560029, \\ Karnataka, India \\ (e-mail: nishanth46@gmail.com). \\ DOI https://doi.org/ \\ 10.1055/s-0041-1742119. \\ ISSN 0976-3147.
}

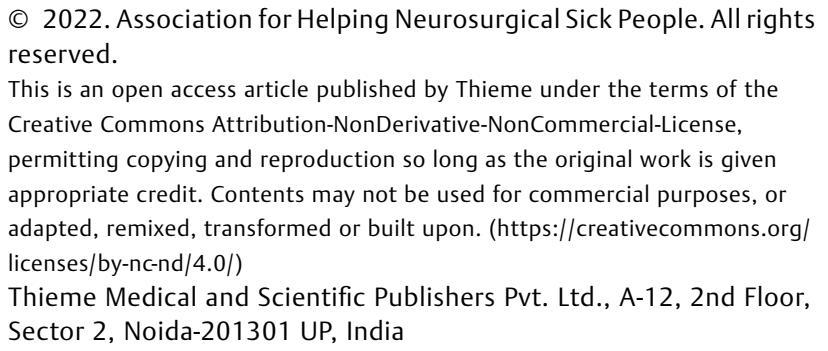

(c) 2022. Association for Helping Neurosurgical Sick People. All rights reserved.

This is an open access article published by Thieme under the terms of the Creative Commons Attribution-NonDerivative-NonCommercial-License, permitting copying and reproduction so long as the original work is given appropriate credit. Contents may not be used for commercial purposes, or adapted, remixed, transformed or built upon. (https://creativecommons.org/ licenses/by-nc-nd/4.0/)

Thieme Medical and Scientific Publishers Pvt. Ltd., A-12, 2nd Floor, Sector 2, Noida-201301 UP, India 
of internal capsule with sharp dose fall out while sparing the surrounding normal tissues. ${ }^{9}$ The dose prescription has refined over the years and has contributed to decrease in adverse effects. $^{4}$

These patients start experiencing clinical benefit by the end of 6 months and reach a plateau by 2 to 3 years after the procedure. ${ }^{5}$ The patient selection needs to be done by multidisciplinary team of neurosurgeon, psychiatrist, neurologist, and behavioral scientists. The guidelines are already established and being practiced throughout the world. Despite proof in the literature and anecdotal case reports from Indian radiosurgical experience, radiosurgical capsulotomy in India is still in its nascent phase. ${ }^{10}$ The "National Advisory Committee" for psychosurgery has specified their criteria for the management of OCD. The Mental Health Act 1987 had not specified anything explicitly about psychosurgery. The Mental Healthcare Act of 2017 is a successor to the earlier legislation and deals with psychosurgery under Section 96 of Chapter $12 .^{11,12}$ This section deals with the indications, admissions, procedure, and discharge summaries.

The relative difference in the popularity of functional neurosurgery for psychiatric indications and neurological indications is secondary to lesser enthusiasms among psychiatrists for psychosurgery. Else psychosurgery might had been equally popular as is the case with various neurological disorders, for example, Parkinson's disease and essential tremor. Such a report is a boost in favor of completely noninvasive treatment modality for the management of a debilitating disorder such as OCD.

\section{Funding}

None.
Conflict of Interest

None declared.

\section{References}

1 Tripathi M, Agrahari A. Why fly over the Cuckoo's nest? Psychosurgery in my brain please. Neurol India 2020;68:1271-1272

2 Tripathi M, Mukherjee K, Chhabra R, Radotra I, Singh AP, Radotra B. Gamma knife for obsessive compulsive disorder: can it be detrimental? Turk Neurosurg 2014;24(04):583-586

3 Tripathi M. Leksell radiosurgery. Neurol India 2020;68:240-241

4 Miguel EC, Lopes AC, McLaughlin NCR, et al. Evolution of gamma knife capsulotomy for intractable obsessive-compulsive disorder. Mol Psychiatry 2019;24(02):218-240

5 Martínez-Álvarez R. Radiosurgery for behavioral disorders. Prog Neurol Surg 2019;34:289-297

6 Lippitz BE, Mindus P, Meyerson BA, Kihlström L, Lindquist C. Lesion topography and outcome after thermocapsulotomy or gamma knife capsulotomy for obsessive-compulsive disorder: relevance of the right hemisphere. Neurosurgery 1999;44(03): 452-458, discussion 458-460

7 Pattankar S, Sankhe M, Chavda K. Efficacy of gamma knife radiosurgery in refractory obsessive-compulsive disorder: An Indian Experience. J Neurosci Rural Pract 2022;13(01):23-31

8 Marc L. Psychosurgery: New Techniques for Brain Disorders. Switzerland: Springer International Publishing; 2014

9 Paddick I. Radiosurgical Capsulotomy for OCD-a dosimetric analysis of 105 treatments, in ISRS Congress. Montreux, Switzerland

10 Doshi PK, Arumugham SS, Bhide A, et al. Indian guidelines on neurosurgical interventions in psychiatric disorders. Indian J Psychiatry 2019;61(01):13-21

11 Antony JT. Mental Health Care Bill-2016: an illusory boon; on close reading it is mostly bane. Indian J Psychiatry 2016;58(04): 363-365

12 Antony JT. On drafting a new Mental Health Act. Indian J Psychiatry 2010;52(01):9-12 